Functional Analysis of Akatek Voice Constructions

Author(s): Roberto Zavala

Source: International Journal of American Linguistics, Vol. 63, No. 4 (Oct., 1997), pp. 439-474

Published by: The University of Chicago Press

Stable URL: http://www.jstor.org/stable/1265736

Accessed: 10/04/2013 08:04

Your use of the JSTOR archive indicates your acceptance of the Terms \& Conditions of Use, available at

http://www.jstor.org/page/info/about/policies/terms.jsp

JSTOR is a not-for-profit service that helps scholars, researchers, and students discover, use, and build upon a wide range of content in a trusted digital archive. We use information technology and tools to increase productivity and facilitate new forms of scholarship. For more information about JSTOR, please contact support@ jstor.org. 


\title{
FUNCTIONAL ANALYSIS OF AKATEK VOICE CONSTRUCTIONS
}

\author{
ROBERTO ZAVALA \\ Max Planck Institute for Psycholinguistics, University of Oregon, \\ AND UNIVERSIDAD DE GUADALAJARA
}

1. Introduction. In this study I investigate the correlation between syntactic structure and pragmatic function of voice alternations in Akatek, a Mayan language of the Q'anjob'alan subgroup. ${ }^{1}$ In Mayan linguistics, voice has been an area of intensive research since the mid-seventies. Past investigations of Mayan voice have moved along three main lines. There have been, first, descriptive studies in which the morphosyntax of several voice alternations in particular languages was reported (Smith-Stark 1976, Bricker 1978, Craig 1979, Mondloch 1981, Ayres 1983, Dayley 1985, and England 1988 , inter alia). Second, there have been a number of comparative and contrastive studies probing the morphosyntactic similarities of voice constructions in different Mayan languages (Smith-Stark 1978 and Dayley 1983, inter alia). Third, there have been more formal discussions, mostly within the Relational Grammar framework (e.g., Aissen 1990), that endeavor to interpret the various alternations of transitive clauses as purely formal devices in which the grammatical status of clausal arguments (subject, object, indirect object) is re-evaluated from a hypothetical "earlier" ("underlying") stratum to an attested "final" ("surface") stratum.

The discussion of voice in Mayan languages received a boost from studies of Australian languages and Eskimo, where it was demonstrated that the antipassive voice construction is one of the most recognizable constructions in ergative languages. In that connection, Smith-Stark (1976; 1978 ) introduced the term "antipassive" into Mayan linguistics, for the purpose of describing a process of detransitivization of semantically transitive, two-argument predicates in which the agent maintains the grammatical role of subject, while the object/patient is suppressed or demoted to oblique.

\footnotetext{
${ }^{1}$ This research was made possible through financial support from the Universidad de Guadalajara and the Fulbright-LASPAU program. Aid from these institutions is greatly appreciated. I am especially indebted to mi tocayo Franco and his extended family, Andrés Juan, Jorge Andrés, and Juana Méndez from San Miguel Acatán, and Eduardo Martínez (from San Rafael la Independencia), who have patiently taught me what I know about their language. Special thanks also to T. Givón and Colette Craig for their comments and suggestions. Any errors are my own responsibility.
} 
Morphosyntactic and comparative studies have demonstrated that Mayan languages have, in addition to the active and the passive clauses, several antipassive constructions. In this connection, the following constructions have been treated as types of antipassives:

(a) agent-in-focus

(b) object incorporation

(c) semi-object incorporation

(d) antipassive with demoted object

These clause types have been considered antipassive on purely structural grounds.

This study deals with the various voice alternations in Akatek. Unlike previous Mayan studies, which have focused almost exclusively on the structural (morphosyntactic) aspects of voice, this paper also investigates the discourse-pragmatic function of the various voice constructions (clause types) that code semantically transitive events.

I begin by defining voice alternations functionally, following earlier works on the discourse pragmatics of voice (Cooreman 1982; 1987, Rude 1985, Thompson 1989, and Givón $1990 ; 1994 a ; 1994 b)$. Within this approach, pragmatic voice alternations are viewed as the mechanisms by which languages encode the different degrees of topicality of the two main participants of a semantically transitive event, agent and patient. Voice constructions are thus defined first by their prototypical pragmatic functions. Following such a functional definition, the typology of voice constructions is the observed cross-language structural variety of each functionally defined voice (Givón 1994a). This typological approach notes first that a certain range of structures can and indeed does fulfill the same discoursepragmatic function in different languages. It also notes that within the same language, related but not identical voice functions can be coded by distinct construction types, i.e., that a language may have more than one active, more than one passive, more than one antipassive, or more than one inverse.

Cooreman (1982; 1987), Rude (1985), Thompson (1989), and the various studies in Givón (1994b) have used quantitative text-based methods for identifying the discourse-pragmatic function of the four major voice alternations: active-direct, inverse, passive, and antipassive. The functional definition of pragmatic voice that emerged from these previous studies is as follows:

(a) Active-direct

Both agent and patient are topical, but the agent is more topical than the patient.

(b) Inverse

Both agent and patient are topical, but, in contrast with the active voice, the patient is more topical than the agent. 
(c) Passive

The patient is topical and the agent is completely nontopical.

(d) Antipassive

The agent is topical and the patient is completely nontopical.

TABLE

Relative Topicality of the Agent and Patient in Semantically Transitive Clauses in the Four Main Pragmatic Voices (CoOREman 1987)

\begin{tabular}{llcc}
\hline \hline Active direct & AGT & $>$ & PAT \\
Inverse & PAT & $>$ & AGT \\
Passive & PAT & $>$ & AGT \\
Antipassive & AGT & $>$ & PAT \\
\hline
\end{tabular}

Schematically, following Cooreman (1987), this may be represented as shown in table 1 .

In this study I show that Akatek expresses all four main pragmatic voices by distinct syntactic constructions. In particular, that besides the previously recognized active, passive, and antipassive, Akatek has a pragmatic INVERSE VOICE. I evaluate the structural and the functional correlates of the various possible candidates for each pragmatic voice. My findings indicate that of the two apparent passives in the language, one indeed conforms to the functional profile of a prototypical passive. The other, however, turns out to better conform to the functional profile of an inverse voice. What is more, Akatek has a second inverse construction which is semantically transitive but syntactically intransitive.

This study also shows that Akatek has several antipassive constructions. The Akatek texts considered in the present study contained enough tokens to assess the pragmatic function of only two of these antipassives. The first, the so-called absolutive antipassive, has a nontopical patient, thus conforming to the prototypical definition in table 1 . The second, however, has a more topical patient (somewhere between the level found for the patient of the active-direct and that of the absolutive antipassive). My study also shows that the Akatek agent-in-focus construction is functionally not an antipassive voice, since it does not suppress the topicality of the patient.

2. Some basic grammatical features of Akatek. Before I discuss the different structural devices that are the focus of this investigation, it is necessary to survey some of the basic facts of Akatek morphosyntax. ${ }^{2}$

\footnotetext{
${ }^{2}$ The data used in this paper come from published texts collected by Peñalosa, Dakin, and me (see references) and my own fieldwork with Akatek people in San Miguel Acatán, Huehuetenango, Guatemala, refugee camps on the Mexico-Guatemala border, and with families that have emigrated to Canada and the United States.
} 
TABLE 2

Akatek Ergative AffiXes (E)

\begin{tabular}{clllll}
\hline \hline \multirow{2}{*}{ Person } & \multicolumn{2}{c}{ Set I (_C) } & & \multicolumn{2}{c}{ Set II (_V) } \\
\cline { 2 - 3 } \cline { 5 - 6 } \cline { 5 - 6 } & Singular & Plural & & Singular & \multicolumn{1}{c}{ Plural } \\
\hline 1 & in- $a n$ & $k u-w e j$ & & $w-a n$ & $-o n / k-w e j(\mathrm{INCL})$ \\
& & $k u-o n$ & & & $-o n / k-$ on $(\mathrm{EXCL})$ \\
2 & $a-$ & $a-w e j$ & & $a w-$ & $e y-\quad w e j$ \\
3 & $s-$ & $s-$ & & $y-$ & $y-$ \\
\hline
\end{tabular}

TABLE 3

Akatek Absolutive Affixes (A)

\begin{tabular}{cll}
\hline \hline Person & Singular & \multicolumn{1}{c}{ Plural } \\
\hline 1 & in ...an & on $/ k u-\ldots$ wej $(\mathrm{INCL})$ \\
& & - on $/ k u-\ldots$ on $(\mathrm{EXCL})$ \\
2 & ach & ach . . wej \\
3 & $\emptyset$ & $\emptyset$ \\
\hline
\end{tabular}

2.1. Person marking and ergativity. Akatek follows an ergativeabsolutive alignment, not in its nominal case marking but in the pronominal affixes that cluster around the verb. The language has three sets of person affixes that conflate person, number, and case: two sets of ergative affixes (table 2) and one set of absolutive affixes (table 3). One of the ergative sets occurs before vowel-initial stems, the other before consonantinitial stems.

Notice, on the one hand, that the absolutive affixes for first-person singular (in . . . an) and plural $(k u-\ldots w e j$ and $k u-\ldots$ on $)$ have the same realization as the ergative set I and, on the other hand, that the absolutive suffix -on is the same as one of the alternates of the first-person plural set II. However, the formal distinction between the two different sets is retained since the absolutive first-person markers do not select distinct subsets depending on whether the following word has an initial consonant or an initial vowel, whereas the ergative set does. Another formal difference is the distribution of the first-person singular marker in: it occurs as a prefix in the ergative function but could also occur as a suffix in the absolutive function.

The ergative pronominal affixes may refer to agents of transitive clauses (1), to possessors (2), or to objects of relational nouns (3), and grammaticalized adpositions (4). ${ }^{3}$ Ergative markers may thus occur as prefixes on either verbs (1), nouns (2 and 3), or adpositions (4).

\footnotetext{
${ }^{3}$ I use the practical orthography recommended by the Academia de las Lenguas Mayas de Guatemala. The following conventions apply: $\left\langle\mathrm{b}^{\prime}\right\rangle=/ \mathrm{b} /,\langle\mathrm{ch}\rangle=/ \mathrm{t} \mathrm{J} /,\langle\mathrm{j}\rangle=/ \mathrm{h} /,\langle\mathrm{tx}\rangle=/ \mathrm{ts} /,\langle\mathrm{tz}\rangle=$
} 
(1a) Agent of transitive clause / $-\mathrm{V}$

maa in-aw-etne

NEG.COM A1s-E2s-deceive

'You didn't deceive me' (Y6/155)

(1b) Agent of transitive clause / _ C

$\begin{array}{lllll}x \text {-in-a-ten } & t e j & y \text { - } u l & j a^{\prime} & t u^{\prime} \\ \text { cOM-A1s-E2s-push } & \text { DIR:hither } & \text { E3-in } & \text { water } & \text { DIS }\end{array}$

'You pushed me into the sea' (Y6/165)

(2a) Possessor of noun / _ C

in-chee an

E1s-horse CL1s

'my horse'

(2b) Possessor of noun / _ V

$\boldsymbol{w}$-on an

E1s-avocado CL1s

'my avocado'

(3) Possessor of relational noun
s-tii-laj
b'ee
$x-\emptyset-$ too
naj
E3-mouth-COL road COM-A3-go PRO/he

'By the sides of the road, he went'

(4) Possessor of grammaticalized adposition

$\begin{array}{lllll}a^{\prime}-\emptyset & \text { wajeb'oj } & \text { pilan } & \text { w-et } & \text { an } \\ \text { give-A3 } & \text { six } & \text { pieces } & \text { E1s-for } & \text { CL1s }\end{array}$

'Give me six eggs!'

The absolutive affixes (table 3) mark the patient of transitive clauses, as in (1) above, and the subject ("single argument") of intransitive (monovalent) predicates, both verbal (5) and nonverbal (6):

(5) Absolutive prefixed to verbal predicate

tol chi-ach-kam eyman

so INC-A2s-die quickly

'So you die quickly' (TX'I/188)

$/ \mathrm{ts} /,\langle\mathrm{x}\rangle=/ \mathrm{s} /,\langle\mathrm{xh}\rangle=/ \mathrm{J} /,\left\langle{ }^{\prime}\right\rangle=/ 7 /, \mathrm{VV}=$ long vowel, and $\mathrm{C}^{\prime}=$ ejective consonant. The grammatical abbreviations used in the examples can be found in $n$. 12. The abbreviations and numbers following the translation of examples indicate the line of the text from which the example was selected. 
(6) Absolutive suffixed to nonverbal predicate ix-ach

woman-A2s

'You are a woman'

(Y2/63)

Absolutive suffixes also follow two adpositions, the dative/benefactive $(t) e(t)$ (7a) and the locative b'ey $(7 b)$ :

(7a) Absolutive suffixed to DAT/BEN

$\begin{array}{lllll}\text { chi- } \emptyset-w-a^{\prime} & k a n & \text { in-na'b'al } & t i & e \text {-ach } \\ \text { INC-A3-E1s-give } & \text { DIR } & \text { E1s-knowledge } & \text { PROX } & \text { to-A2s }\end{array}$

'I give you my knowledge' (T4/56)

(7b) Absolutive suffixed to the LOC b'ey

$\begin{array}{llllll}x-\emptyset \text { - } b^{\prime} e t & e b^{\prime} & n a j & e c h e & t x^{\prime} \text { otx' } & \text { b'ey-ach } \\ \text { COM-A3-go } & \text { PL } & \text { PRO } & \text { size } & \text { land } & \text { at-A2s }\end{array}$

'They went to measure the land at your place (where you are)'

The absolutive affix referring to the patient of transitive clauses can occur in two positions: preceding the ergative marker (8) or following the transitive verbal stem $(9):^{4}$

(8) A-E-V order of affixes

$\begin{array}{llllll}\text { chi-ach-w-a' } & o k & j u n & a a b^{\prime} i l & y \text { - } u l & t e^{\prime} \\ \text { INC-A2s-E1s-put } & \text { DIR:in } & \text { one } & \text { year } & \text { E3-in } & \text { wood }\end{array}$

'I will put you in jail for one year' (Y6/170)

(9) E-V-A order of affixes

$\begin{array}{lllll}\text { chi-in-q'oj-ach } & \text { ey-toj } & b^{\prime} e y-\emptyset & t i & a n \\ \text { INC-E1s-throw-A2s } & \text { DIR:down-DIR:thither } & \text { at-A3 } & \text { PROX } & \text { CL1s }\end{array}$

'I'll throw you down from here' (TX'I/119)

In addition to referring to the patient of the transitive ( 8 and 9), an absolutive marker can also be affixed to a verbal auxiliary that directly precedes such a verb. Akatek has several such auxiliaries, some verbal, others nonverbal, which together with a transitive verb form complex two-predicate (P1-V2) clauses. The first predicate (P1) in such a clause, whether verbal or nonverbal, displays the finite features of a main verb, such as tense-aspect modal marking. The second predicate (V2), semantically the main verb, is grammatically nonfinite. In some cases, the diachronic process of clause integration ("clause union") is advanced enough so that the absolutive affix referring to the patient does not appear on the semantically appropriate

\footnotetext{
${ }^{4}$ The conditions which yield the alternate position of the absolutive affix are yet to be determined.
} 
transitive verb, but rather on the semantically inappropriate (intransitive) auxiliary $(10 a)$. In other cases, when the clause is not quite as integrated, the absolutive affix remains on the semantically appropriate transitive verb $(10 b)$, i.e., where it is normally found in simple transitive clauses:

(10a) Integrated: semantic patient affixed to auxiliary verb

$\begin{array}{lll}x \text {-ach-b'et } & w \text {-il } & a n \\ \text { COM-A2s-go } & \text { E1s-see } & \text { CL1s }\end{array}$

'I went looking for you'

(10b) Nonintegrated: semantic patient affixed to embedded verb

$x$-in-b'et ach-w-il an
COM-A1s-go A2s-E1s-see CL1s
'I went to look for you'
('I went and looked for you')

The distribution of person markers in the more integrated clause (10a) suggests that the two predicates have become COLEXICALIZED (see Zavala $1993 b)$.

2.2. Split ergativity. The ergative-absolutive distribution of pronominal affixes in Akatek changes into a nominative-accusative distribution in certain contexts of grammatical complexity, in embedded clauses that follow three types of "higher" predicates:

(a) following the main verb il 'see'

(b) following some adverbial predicates

(c) following some other grammaticalized auxiliaries

In such contexts, the embedded clause is historically either the grammatical subject or object of the "higher" predicate, and thus historically NOMINALIZED. Such clauses reveal three morphosyntactic peculiarities. First, the embedded verb cannot inflect for aspect, thus revealing its nonfinite status. Second, a nominalizing suffix (-on) marks the embedded verb when it is transitive. And third, the embedded clause maintains a nominative-accusative distribution of the pronominal affixes instead of the ergative-absolutive alignment found in simple clauses: The ergative (E) marker now refers to the subjects of both transitive and intransitive clauses. This is so presumably because the embedded clauses are historically nominalized, so their subjects - whether transitive or intransitive - are marked as POSSESSORS. And the ergative and possessor affixes in Akatek are one and the same (see table 4).

In (11) below, a monovalent (intransitive) "higher" predicate takes the lower clause as its absolutive subject, and this clause can be either intransitive $(11 a)$ or transitive $(11 b)$ : 
(11a) Subject complement, intransitive watx' $-\emptyset \quad \boldsymbol{a}$-wey- $i$ good-A3 E2s-sleep-INTR

'It's good that you sleep'

(Lit., 'It is good, your sleeping')

(11b) Subject complement, transitive
sa'al- $\emptyset \quad \emptyset$-ey-i'-on-aa-tej
good-A3 A3-E2p-carry-NOM-DIR:up-DIR:hither
ey-ats'am
E2p-salt

'It's good that you pick up your salt'

(Lit., 'It is good, your picking up your salt')

In (12) below, the complement clause functions as the grammatical object of the transitive "higher" verb il 'see'. The complement verb is intransitive in (12a) and transitive in $(12 b)$ :

(12a) Object complement, intransitive
$x-\emptyset-y-i l$
ix $\quad$ aw-el-toj
COM-A3-E3-see she E2s-leave-DIR:thither

'She saw you leaving'

(Lit., 'She saw it, your leaving')

(12b) Object complement, transitive

$\begin{array}{llll}x-\emptyset-y-i l & i x & \text { in-aw-ante-on } & \text { an } \\ \text { COM-A3-E3-see } & \text { she } & \text { A1s-E2s-cure-NOM } & \text { CL1s }\end{array}$

'She saw that you cured me'

(Lit., 'She saw it, your curing me')

In the same vein, the complements of the auxiliaries laawi 'terminative', xew 'terminative', lanan 'progressive', and sq'e 'be able' appear as nonfinite clauses whose pronominal affixes follow a nominative-accusative distribution. Thus compare (11a) and (11b) above with (13a) and (13b) below. The progressive lanan is derived historically from the nonverbal predicate 'extended':

(13a) Auxiliary + V2, intransitive

lanan- $\emptyset-\quad a$-wey- $i$

PROG-B3 E2s-sleep-INTR

'You are sleeping'

(Lit., 'Your sleeping extends')

(13b) Auxiliary + V2 transitive

lanan- $\emptyset$ - $\emptyset$-ey-i'-on-aa-tej

ey-ats'am

PROG-A3

A3-E2p-carry-NOM-DIR:up-DIR:hither

E2p-salt

'Y'all are picking up your salt'

(Lit., 'Your picking up your salt extends') 
TABLE 4

Distribution of Ergative and Absolutive Affixes

\begin{tabular}{lcccccc}
\hline & AGT & PAT & SUBJ & POSS & X-ADP & ADP-X \\
\hline ERG: & + & - & + & + & + & - \\
ABS: & - & + & + & - & - & + \\
\hline
\end{tabular}

In table 4, the distribution of the ergative and the absolutive pronominal markers in Akatek is summarized. The ergative affix can refer to the agent or possessor, or to the nominative subject of a special set of nonfinite embedded clauses. The absolutive affix can refer to the patient of transitives, the subject of intransitives, or the object of the adpositions coding dative/ benefactive and allative.

2.3. Word order. Verbal and nonverbal predicates carrying the pronominal affixes in Akatek may appear without overt agent or patient NPs (or independent pronouns). The pronominal affixes on the verb thus in effect function as anaphoric pronouns:

(14) k'am chi-in-aw-oche

NEG INC-A1s-E2s-want

'you don't love me'

$(\mathrm{Y} 6 / 167)$

(15) $\emptyset-q-i ' \quad$ in

A3-E1p-carry then

'we will get one then'

(16) $\quad c h i-\emptyset-y-a^{\prime} \quad$ low $-o j$

INC-A3-E3-put eat-IRR

'he feeds them'

(Lit., 'he lets them to eat')

(RIM2)

When nonfocused, nontopicalized NPs occur in text, they invariably follow the verb, so that Akatek may be considered a verb-initial language. While the agent and patient NPs are obligatorily coded on the verb by pronominal affixes, full NPs display no nominal case marking. When the agent and patient NPs are overtly present, the V-S or V-AGT-PAT orders are most common:

(17) Intransitive clause (V-S)

$\begin{array}{lll}\max \quad \emptyset \text {-too } & e b ' & \text { xin } \\ \mathrm{COM} \quad \mathrm{A} 3 \text {-go.from.there } & \mathrm{PRO} \text { PL } & \text { then } \\ \text { 'and so they went' } \quad(\mathrm{Y} 2 / 17) & \end{array}$


(18) Transitive clause (V-AGT-PAT)

\begin{tabular}{|c|c|c|c|c|c|}
\hline $\begin{array}{l}\text { chix- } \emptyset-y-i l \\
\text { INC-A3-E3-see }\end{array}$ & $\begin{array}{l}i x \\
\mathrm{NCL}\end{array}$ & $\begin{array}{l}\text { ixnam } \\
\text { old.lady }\end{array}$ & $\begin{array}{l}t u^{\prime} \\
\text { DIST }\end{array}$ & $\begin{array}{l}\text { jun } \\
\text { one }\end{array}$ & $\begin{array}{l}\text { kaxha } \\
\text { box }\end{array}$ \\
\hline
\end{tabular}

While the more frequent (unmarked) order is V-AGT-PAT order, Akatek retains a considerable degree of word-order flexibility. ${ }^{5}$ In transitive clauses, the agent and patient NPs can appear in either the V-AGT-PAT or V-PATAGT order. The V-AGT-PAT order is illustrated in (18) above and the V-PAT-AGT order in (19):

(19) Transitive clause (V-PAT-AGT)

$\begin{array}{lllllll}\max & \emptyset \text {-y-etne } & \text { patron } & t u^{\prime} & \text { jun } & \text { rimares } & t u^{\prime} \\ \text { COM } & \text { A3-E3-deceive } & \text { boss } & \text { DIST } & \text { one } & \text { Rimares } & \text { DIST }\end{array}$

'Rimares had deceived the boss' (RIM1/122)

Indirect or oblique NPs in Akatek are marked by either a preposition or a relational noun. Prepositions carry either an ergative or absolutive affix referring to the oblique participant:

(20) Dative participant

$\begin{array}{llll}a w-a \text {-in } & \text { tet- } \square & \text { naj } & \text { an } \\ \text { E2s-put-A1s } & \text { to-A3 } & \text { he } & \text { CL1s }\end{array}$

'You will offer me to him' (NAJ/276)

(21) Locative participant

$\begin{array}{cllllll}\text { max } & \emptyset \text {-s-pix-on } & \text { ok } & \text { naj } & \text { y-iin } & \text { jun lawuxh } \\ \text { COM } & \text { A3-E3-tie-NOM } & \text { DIR } & \text { he } & \text { E3-in } & \text { one } & \text { nail } \\ \boldsymbol{y} \text {-iin } & \text { s-kaxhail } & \text { kamom } & \text { tu' } & & & \\ \text { E3-in } & \text { E3-box } & \text { death } & \text { DIST }\end{array}$

'he attached it to a nail on the coffin' (Y2/24)

Nominals in Akatek can be placed in front of the verb in two pragmatic contexts - topicalization and focusing. Focused and topicalized clauses are formally distinct when the fronted NP is the agent. The verb in topicalized agent clauses displays the same morphological marking as in the V-first (neutral) active clause. Thus, compare (22a) and (22b) below:

(22a) Nontopicalized agent

$\begin{array}{llll}x \text { - } \emptyset \text {-w-ujte } & \text { ok } & \text { naj } & \text { an } \\ \text { COM-A3-E1-chase } & \text { DIR:in } & \text { PRO:man } & \text { CL1s } \\ \text { 'I forced him' } & & & \end{array}$

${ }^{5}$ See Zavala (1992) and Schüle (1993) for more details about word-order flexibility in Akatek. 
(22b) Topicalized agent

$$
\begin{array}{lllll}
\text { jain } & x \text { - } \emptyset \text {-w-ujte } & \text { ok } & \text { naj } & \text { an } \\
\text { I } & \text { COM-A3-E1-chase } & \text { DIR:in } & \text { PRO:man } & \text { CL1s } \\
\text { 'but I (TOPICALIZED), I forced him' } & \multicolumn{2}{c}{(\text { Y55/110) }}
\end{array}
$$

When the topicalized NP is a third-person agent, a resumptive pronoun coreferential to the fronted agent must appear after the verb:

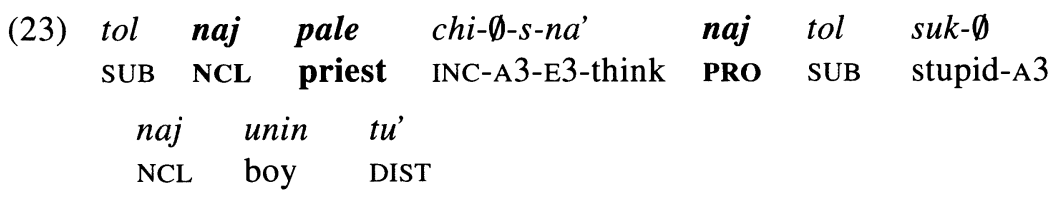

'Since the priest (TOPICALIZED) thought the boy was stupid' (TX'I/234)

The agent-in-focus clause displays a different morphosyntax: $(a)$ The agent-in-focus is preceded by the cleft-focus particle $j a$ '. (b) The verb morphology changes, in comparison to nonfocus clauses. $(c)$ A third-person agent-in-focus construction disallows a coreferential resumptive pronoun $(25 c)$. This is illustrated in $(24 b)$ and $(25 b)$ below. In such agent-in-focus clauses, the transitive verb displays no ergative pronominal affix corresponding to the agent, but only the absolutive affix corresponding to the patient. Further, the verb stem is marked with the suffix -on. Synchronically, one may consider -on in the context of this construction as an agent-in-focus marker (see 3.2 below):

(24a) Nonfocused transitive clause

$\begin{array}{ll}\emptyset \text {-w-ootaj } & \text { an } \\ \text { A3-E1s-know } & \text { CL1s }\end{array}$

'I know that'

(24b) Agent-in-focus transitive clause

ja'-in-k'al Đ-ootajne-on an

FOC-A1-DUR A3-know-AGTFOC CL1s

'only I know that' (Y1/122)

(25a) Nonfocused transitive clause

max in-s-chej tej ix an

COM -A1-E3-force DIR:hither PRO:woman CL1s

'she forced me (to come here)' (TX'I/45)

(25b) Agent-in-focus transitive clause

$\begin{array}{llllll}\boldsymbol{j} \boldsymbol{a}^{\prime}-\emptyset & i x & \text { in-txutx } & \text { an } & \boldsymbol{j} \boldsymbol{a}^{\prime}-\emptyset & i x \\ \text { FOC-A3 } & \text { NCL } & \text { E1-mother } & \text { CL1s } & \text { FOC-A3 } & \text { PRO:woman }\end{array}$




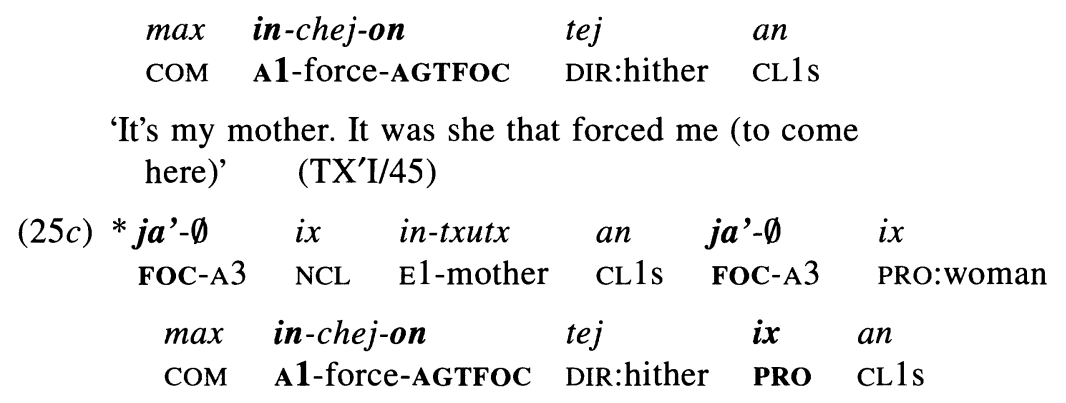

First- and second-person independent pronouns occur only when the participant has been fronted. In contrast, third-person independent pronouns, which may correspond to any of the thirteen noun classes, ${ }^{6}$ can appear in both fronting and nonfronting (neutral) contexts.

3. Voice clause types. In this section I survey the clause types selected as candidates for the quantified study of pragmatic voice functions in Akatek. The quantitative methodology and the results of the study are presented in subsequent sections. Since my methodology involves the assessment of the relative topicality of the agent and patient, the clause types investigated are all syntactic variations on the underlying semantic theme of TRANSITIVE EVENT, i.e., an event involving both an agent and a patient (Hopper and Thompson 1980).

3.1. The active direct clause. From a purely structural perspective, Akatek has three major subtypes of active transitive clauses. All three have a transitive verb inflected for both the ergative agent and absolutive patient. They differ only in word order, and thus only when overt NPs (including independent pronouns) are present. The three variants are:

(a) V-initial

(b) fronted agent

(c) fronted patient

As noted earlier (2.3), Akatek displays a considerable degree of word-order flexibility. In V-initial clauses, both the V-AGT-PAT and the V-PAT-AGT orders are found in texts. A recent pilot study on narrative texts has shown the frequency of the two orders in the speech of older speakers to be 71 percent V-AGT-PAT vs. 29 percent V-PAT-AGT. Their speech in this genre thus tends strongly toward V-AGT-PAT. This tendency was reversed in the

\footnotetext{
${ }^{6}$ See Zavala (1991; 1992).
} 
speech of younger speakers: 37 percent V-AGT-PAT vs. 63 percent V-PATAGT (Schüle 1993). ${ }^{7}$ The two orders are illustrated in:

(26a) V-PAT-AGT order

$\begin{array}{llll}\text { tala } & \text { chi- } \emptyset-y-a & a-m u l n a-i l & n a j \\ \text { maybe } & \text { INC-A3-E3-put } & \text { E2-work-NOM } & \text { PRO:man }\end{array}$

'maybe he will give you some work'

(Lit., 'maybe he will put your work') (NAJ 7)

(26b) V-AGT-PAT order

$\begin{array}{lllll}\text { chi- } \emptyset-s-q \text { 'an } & n a j & \text { unin } & t u^{\prime} & s-m u l n a-i l \\ \text { INC-A3-E3-ask } & \text { NCL } & \text { boy } & \text { DIST } & \text { E3-work-NOM }\end{array}$

'the boy is asking for his work' (NAJ 19)

The active transitive clause with fronted agent, whether topicalized or focused, has been discussed earlier (see 22-25 above). The patient of the active transitive clause can also be fronted, for the purpose of either topicalization or focusing. Unlike agent topicalization, third-person patient topicalization requires no postverbal resumptive pronoun. Further, unlike in agent focusing, the verb in the patient-in-focus clause is not marked by the suffix -on:

(27a) Topicalized patient (no resumptive pronoun)

$\begin{array}{cccccc}\text { tol no' yalixh } & \text { icham wakax } \emptyset \text {-aw- } a \text {, } & \text { tet- } \emptyset \\ \text { that NCL little } & \text { old.man cow } & \text { A3-E2s-put } & \text { to-A3 } \\ \text { naj } & \text { ko-meeb'a unin, peena- } \emptyset & \text { no' } & \\ \text { NCL } & \text { E1p-poor boy bad-A3 } & \text { PRO:animal } & \end{array}$

'The little bull that you gave to your servant is real mean' (NAJ/67)

(27b) Focused patient (no nominalizer)

$\begin{array}{llllll}j a^{\prime}-\emptyset & j u n & a \text {-wakax } & t i & \emptyset \text {-in-chi' } & \text { an } \\ \text { FOC-A3 } & \text { one } & \text { E2s-cow } & \text { PROX } & \text { A3-E1s-bite } & \text { CL1s }\end{array}$

'It's your bull that I'm going to eat' (NAJ 170)

${ }^{7}$ Zavala (1992) and Schüle (1993) have shown that the role of the participants in transitive clauses with two nominals and the verb in initial position is disambiguated by the rank that the participants occupy in an inherent saliency hierarchy. This hierarchy can be decomposed into several familiar subhierarchies: animacy, word class, and reference/individuation/definiteness. The animacy hierarchy predicts that humans are treated as agents in preference over nonhuman participants of active transitive clauses. Animates are treated as agents in preference over inanimates, etc. The word-class hierarchy predicts that pronouns are treated as agents in preference over nouns, proper nouns over common nouns. Finally, the hierarchy of referenceindividuation-definiteness predicts that more referential, individuated, or definite NPs are treated as agents in preference over nonreferential, nonindividuated, indefinite NPs. 
3.2. The agent-in-focus clause. As noted earlier (2.3), the agent-infocus construction displays a number of structural features that distinguish it from other fronted NP clauses. First, the verb is marked as detransitive in the sense that it is inflected only for the absolutive/patient but not for the ergative/agent. Second, the verb is suffixed with the agent-in-focus suffix -on. This can be seen again in (28a) and is also underscored by the ungrammaticality of $(28 b)$ :

(28a) Agent-in-focus clause, absolutive marking

\begin{tabular}{|c|c|c|}
\hline $\begin{array}{l}\text { ja'-in } \\
\text { FOC-A } 1 \mathrm{~s}\end{array}$ & $\begin{array}{l}\emptyset \text {-ij-on-toj } \\
\text { A3-back.carry-AGTFOC-DIR:thither }\end{array}$ & $\begin{array}{l}n a j \\
\text { NCL }\end{array}$ \\
\hline (II) & carried & \\
\hline $\begin{array}{l}{ }^{*} j a^{\prime}-i n \\
\quad \text { FOC-A } 1 \mathrm{~s}\end{array}$ & $\begin{array}{l}\emptyset \text {-w-ij-on-toj } \\
\text { A3-E1-back.carry-AGTFOC-DIR }\end{array}$ & $\begin{array}{l}n a j \\
\text { NCL }\end{array}$ \\
\hline
\end{tabular}

Another fact also underscores the detransitive status of the verb in agentin-focus clauses. Two verb suffixes in Akatek are used to signal transitivity. The "thematic vowel" suffix $-i$ marks intransitive verbs, and the "thematic vowel" suffix $-a$ (with allomorphs $-u$ and $-o$ ) marks transitive verbs. These suffixes appear only when the verb is the last element of the clause. The verb in the agent-in-focus construction is suffixed with the intransitive suffix $-i$. Thus compare:

(29a) Intransitive verb with $-i$ suffix

$k^{\prime} a m-k$ 'al chi- $\emptyset-j u l-i$

NEG/INC-DUR INC-A3-arrive.here-INTR

'he hasn't returned' (JUN1/144)

(29b) Agent-in-focus clause with the $-i$ suffix

$\begin{array}{lllll}j a^{\prime}-\emptyset & \text { naj } & \text { ko-yaawil } & j a^{\prime}-\emptyset & n a j \\ \text { FOD-A3 } & \text { NCL } & \text { E1p-chief } & \text { FOC-A3 } & \text { PRO } \\ \text { chi- } \emptyset \text {-al-on- } i & & & \\ \text { INC-A3-say-AGTFOC-INTR } & & \end{array}$

'It's our king, it is he that has ordered it' (NAJ 104)

In some Mayan languages, agent-in-focus clauses have been formally treated as antipassives. ${ }^{8}$ Structurally, the agent-in-focus clause in Akatek does not seem to be such an antipassive. First, the absolutive affix on the verb refers to the PATIENT, not the agent. Second, the patient is not demoted to oblique, and the verb is still marked by the intransitive suffix. Moreover,

\footnotetext{
${ }^{8}$ In Kekchi' and Tz'utujil (Dayley 1983), an antipassive suffix marks the verb when the agent is focused, and the verb is de-transitivized, although by different means than in Akatek.
} 
the Akatek agent-in-focus clause does not resemble a passive structurally, since its agent is not demoted. What this study shows is that, structure aside, the agent-in-focus clause in Akatek fulfills the discourse-pragmatic function of neither the passive nor the antipassive. If anything, it seems to be somewhat reminiscent, functionally, of an INVERSE since both the agent and the patient retain their high topicality status (see the discussion below).

3.3. Passive clauses. Akatek has two types of passive clauses. In both, the semantically transitive verb is marked by one of three passive suffixes, $-l e,-c h a$, or - $b^{\prime} i l$. The intransitive nature of these clauses is underscored by the fact that the passive verb is inflected only for the absolutive patient but not for the ergative agent. I discuss the two types in order.

3.3.1. The impersonal (agentless) passive. Compare first the active direct clause (30a) with the IMPERSONAL (AGENTLESS) PASSIVE (30b), in this case marked by -le:

(30a) Active transitive

$\begin{array}{llll}x \text { - } \emptyset \text {-in-tx'otx' } & s \text {-mulna-il } & \text { naj } & \text { unin tet } \\ \text { COM-A3-E1s-teach } & \text { E3-work-NOM } & \text { NCL } & \text { boy to }\end{array}$

'I showed (to) the boy his job'

(30b) Impersonal passive (-le)

$\begin{array}{lllll}\text { max } & \emptyset \text {-tx'ox-le } & \boldsymbol{s} \text {-mulna-il } & \text { naj } & \text { unin } \\ \text { COM } & \text { A3-show-PASS } & \text { E-work-NOM } & \text { NCL:man } & \text { boy }\end{array}$

'The job was shown (to) the boy'

(Lit., 'The boy's job was shown') (NAJ 31)

In this type of passive, the agent cannot be overtly expressed.

3.3.2. Agented passive. In the agented passive clauses in Akatek, the agent is expressed overtly in an oblique phrase marked by the prepositional relational noun - $u u$ 'by', 'because of '. The relational noun is prefixed by an ergative person marker cross-referencing the demoted agent. Unlike Tzotzil (Aissen 1987), which does not allow first or second persons as demoted

The verb is inflected for the ABSOLUTIVE agent, while the patient is demoted to oblique and thus corresponds to no inflectional affix on the verb:

(a) Active (Kekchi')

$x$-at-in-sak,

COM-A2s-E1s-hit

'I hit you' (Dayley 1983:27)

(b) Agent-in-focus antipassive (Kekchi')

laa'at $\quad x$-at-sak'-o-k w-e

you COM-A2s-hit-AP-IT E1s-to

'It was you who hit me' (Dayley 1983:29) 
agents of this type of a passives, Akatek allows first- and second-person oblique agents in such clauses. The suffix $-b^{\prime} i l$ is used in the PERFECTIVE PASSIVE variant, instead of the suffix -le. Thus compare:

(31a) Agented passive (-le) chi- 0 -tzu'-le naj $\boldsymbol{y}$-uu $e b^{\prime}$ INC-A3-reprimand-PASS PRO:man E3-by them 'he was scolded by them' (Y6/136)

(31b) Perfective agented passive (- $\left.b^{\prime} i l\right)$ jax wan no' chee ti' i'-b'il- $\emptyset$ thus DEFPL NCL horse PROX carry-PASS/PF-A3

$$
\begin{array}{ll}
\text { ay- } u u & t i \\
\text { E2p-by } & \text { PROX }
\end{array}
$$

'and these horses that have been brought by you all ...' (NAJ/637)

(31c) Perfective agented passive (- $\left.b^{\prime} i l\right)$

$\begin{array}{cllll}\text { tol } & \boldsymbol{i}^{\prime} \text {-b'il- } \emptyset & s-p a j & \text { jun } & \text { juun } \\ \text { because } & \text { carry-PASS/PF-A3 } & \text { E3-reply } & \text { one } & \text { paper } \\ t u & \boldsymbol{w} \text { - } u \text { ' } & & & \\ \text { DIST } & \mathbf{E} 1 \mathbf{s}-\mathrm{by} & & & \end{array}$

'since the reply to the letter has been brought by me' (TX'I/291)

The suffix -cha is the third passive suffix that occurs in both personal and impersonal passive constructions. The suffix -cha carries an ADVERSIVE PASSIVE sense (referring to the patient), usually coupled with an "ability" or "achievement" sense (referring to the agent). Thus compare:

(32a) Neutral passive (suffix -le)

ach-ij-le w-uu an

A3s-back.carry-PASS E1s-by CL1s

'you were carried by me'

(32b) Adversive passive (suffix -cha)

ach-ij-cha w-uu an

A2s-back.carry-PASS E1s-by CL1s

'I was able to carry you (to your detriment)'

(32c) Adversive passive (suffix -cha)

tejan maa Ø-mitx'-cha no' s-me' naj

perhaps NEG/COM A3-grab-PASS NCL E3-sheep PRO:man

'his sheep couldn't be caught'

(NAJ/422) 
(32d) Adversive passive (suffix - cha)

$\begin{array}{lllll}k^{\prime} a m & c h-\emptyset-i j-c h a & \text { kusilal } & w-u u & \text { an } \\ \text { NEG/INC } & \text { INC-A3-back.carry-PASs } & \text { sadness } & \text { E1s-by } & \text { CL1s }\end{array}$

'I couldn't bear the sadness'

(Lit., 'the sadness could not be borne by me')

(ALE 324)

3.4. Antipassive clauses. Akatek has three antipassive constructions, designated by the Mayanist tradition according to their structural features:

(a) absolutive antipassive

(b) incorporating antipassive

(c) demoted patient antipassive

I survey them in order.

3.4.1. The absolutive antipassive. In the absolutive antipassive, the semantically transitive verb stem is marked with the antipassive suffix $-w(i)$. The verb is inflected as intransitive, with the absolutive pronominal marker referring to the AGENT. The patient in this construction is neither overtly expressed nor inflected on the verb. Thus compare:

(33a) Active transitive

$\begin{array}{cccccc}\text { too-oj } & \emptyset-\text { ko-lo' } & \text { jun-oj } & \text { tzetal } & \text { y-ul-laj } & \text { wan } \\ \text { go-IRR } & \text { A3-E1p-eat } & \text { one-IRR } & \text { things } & \text { E3-in-COL } & \text { DEFPL } \\ \text { mimej } & \text { konob } & & & & \\ \text { big } & \text { village } & & & & \end{array}$

'let us go and eat in the big towns'

$(\mathrm{Y} 6 / 4)$

(33b) Absolutive antipassive

$\begin{array}{lll}\text { ta } & \text { chi-on-lo'-w } & \text { on } \\ \text { COND } & \text { INC-A1p-eat-AP } & \text { CL1p }\end{array}$

'if we eat' (Y3/140)

(33c) Absolutive antipassive

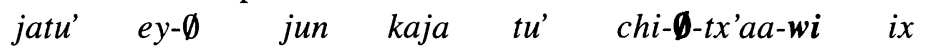

there EX-A3 one box DIST INC-A3-wash-AP NCL

$\begin{array}{lll}\text { ixnam } & j u n & k^{\prime} u \\ \text { old.woman } & \text { one } & \text { day }\end{array}$

'the box came one day to where an old woman was washing' $(\mathrm{Y} / 139)$

3.4.2. The incorporating antipassive. In the incorporating antipassive clause, the verb is marked by the same antipassive suffix -wi. Likewise, the verb carries only an absolutive affix referring to the agent, but the patient is not totally absent here. Rather, it appears immediately after the verb. This 
patient is nonreferring, nonindividuated, and can carry no determiners. It thus closely resembles an incorporated object. The incorporated status of the patient in this antipassive clause is underscored by the fact that in the active transitive the patient may appear in either one of the two orders, V-AGT-PAT or V-PAT-AGT. In the incorporating antipassive, however, only the V-PAT-AGT order is possible. That is, the patient must be adjacent to the verb. Thus compare:

(34a) Active transitive, V-PAT-AGT

$\begin{array}{lllll}x \text { - } \emptyset \text {-s-nooch-toj } & \text { ixim } & \text { aan } & \text { no' } & \text { txitam } \\ \text { COM-A3-E3-eat.biting-DIR } & \text { NCL } & \text { corncob } & \text { NCL } & \text { pig }\end{array}$

'the pig ate the corncob'

(34b) Active transitive, V-AGT-PAT

$\begin{array}{lllll}x-\emptyset \text {-s-nooch-toj } & \text { no' } & \text { txitam } & \text { ixim } & \text { aan } \\ \text { COM-A3-E3-eat.biting-DIR } & \text { NCL } & \text { pig } & \text { NCL } & \text { corncob }\end{array}$

'the pig ate the corncob'

(34c) Incorporative antipassive, V-PAT-AGT

$x$ - 1 -nooch-wi aan no' txitam

COM-A3-eat.biting-AP corncob NCL pig

'the pig was eating the corncob'

$(34 d) *$ V-PAT-AGT:

$* x-\emptyset$-nooch-wi no' txitam aan

COM-A3-eat.biting-AP NCL pig corncob

The nonreferring nature of the incorporated patient is underscored by its failure to take determiners. Thus compare:

$(35 a)$
ach-nooch-wi aan
B2s-eat.biting-AP corncob
'you were eating corncob'

$\begin{array}{lll}* \text { ach-nooch-wi } & \text { ixim } & \text { aan } \\ \text { A2s-eat.biting-AP } & \text { NCL } & \text { corncob }\end{array}$

$(35 b)$

3.4.3. The demoting antipassive. In the demoting antipassive, the verb is also marked by an antipassive suffix (-wi or $-w a)$ and is inflected only for the absolutive agent. The patient, however, appears as an oblique nominal prefixed by the locative relational noun -iin. That locative noun is marked by the ergative/genitive pronominal referring to the patient, as in:

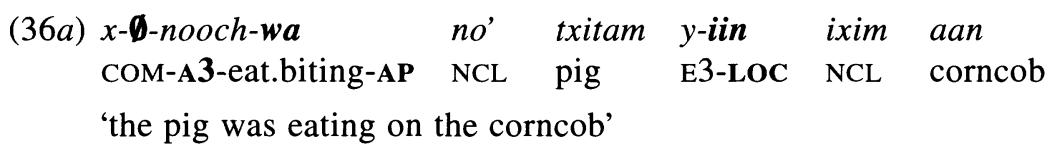




\section{(36b) ch-ach-tx'aa-wi y-iin pitchile INC-A2s-wash-AP E3-LOC cloth \\ 'you are washing at the clothes'}

The patient in this antipassive construction follows the agent rather than the verb (36a), can be modified by a determiner ( $36 a)$, and can be referring and individuated.

3.5. The VP nominalization. Akatek has another clause type with a seemingly incorporated, nonreferring, nonindividuated patient. This clause is grammatically nominalized and has been treated by Craig (1979) in Jakaltek, a related language within the Kanjobalan subgroup, as a subtype of incorporating antipassive. An example of this can be seen in the Akatek wH-question:

$$
\begin{aligned}
& \text { b'ey- } \emptyset \text {-tu' max-ach-b'et il-o me ma'i' } t i^{\prime} \\
& \text { where-A3-DIST COM-A2s-go see-NOM sheep today PROX } \\
& \text { 'Where did you go to watch the sheep today?' (NAJ/405) }
\end{aligned}
$$

The semantically transitive verb bears no personal affixes at all and is further marked by the nominalizer suffix $-o /-e$. Semantically, the patient in this construction is just as nonreferring, unindividuated, and determiner-less as in the incorporating antipassive. In Craig's (1979) analysis, the agent of the transitive verb in this clause type is missing due to Equi-Subject deletion. However, the same nominalized structure can be the subject of a nonverbal predicate (38a) or the object of a preposition (relational noun):

(38a) Subject of nonverbal predicate

$$
\begin{aligned}
& \text { watx'- } \emptyset \quad \text { il-o' } \quad m e^{\prime} \\
& \text { good-A3 see-NOM sheep } \\
& \text { 'it is good to watch sheep' } \\
& \text { (Lit., 'watching sheep is good') }
\end{aligned}
$$

(38b) Object of preposition

$\begin{array}{llll}\max -\emptyset \text {-ok } & \text { naj } \quad y \text {-iin } & u k \text { '-e } & \text { an } \\ \text { COM-A3-enter he } \quad \text { E3-in } & \text { drink-NOM } & \text { liquor } \\ \text { 'and so he began to drink' } & (\mathrm{Y} 3 / 35)\end{array}$

From a purely structural perspective, then, this clause type is better treated as an agentless VP NOMINALIZATION rather than an antipassive. ${ }^{9}$

3.6. The inverse clause. In the Akatek construction I have chosen to call the inverse, the patient is the absolutive subject of a bona fide intransitive verb that corresponds, semantically, to a particular transitive verb. The

\footnotetext{
${ }^{9}$ The VP nominalization with a nonreferring object often functions as an antipassive elsewhere, as in English he went deer-hunting last week, he loves trout-fishing, he's a junk-collector.
} 
agent appears as an oblique nominal, marked by the same preposition (relational noun) that marks the agent-of-passive (see above). The intransitive verb in the inverse clause is inflected only for the absolutive patient. The verb is thus grammatically intransitive, and the clause as a whole resembles, structurally, an agented passive. I argue, however, that this clause type functions as an inverse in Akatek. ${ }^{10}$ Compare first the active and its corresponding inverse:

(39a) Active transitive

$\begin{array}{lllllll}\max & \emptyset-y-i i & \text { toj } & \text { naj } & \text { unin } & \text { no' } & \text { wakax } \\ \text { COM } & \text { A3-E3-carry } & \text { DIR:thither } & \text { NCL } & \text { boy } & \text { NCL } & \text { cow }\end{array}$

'the bull took the boy away'

(39b) Inverse

$\begin{array}{lllllll}\max & \emptyset \text {-too } & \text { naj } & \text { unin } & \text { y-uu } & \text { no' } & \text { wakax } \\ \text { COM } & \text { A3-go } & \text { NCL } & \text { boy } & \text { E3-by } & \text { NCL } & \text { cow }\end{array}$

'the bull took the boy away'

(Lit., 'the boy went by the bull')

(NAJ 128)

Unlike the agented passive, this inverse clause in Akatek uses only intransitive verbs. Unlike the impersonal (agentless) passive, the agent is overtly present in the inverse clause. Thus compare:

(40a) Impersonal passive $\begin{array}{lll}\max -\mathbf{0}-m a \text {-le } & \mathrm{kam} & \text { naj } \\ \text { COM-A3-hit-PASS } & \text { die } & \text { PRO:man }\end{array}$

'he was killed'

(40b) Inverse

$\begin{array}{cllllll}\text { txekel- } \emptyset & \text { b'ey } & \text { max } & \emptyset \text {-kam } & \text { naj } & \text { - } \text {-uu } & n o^{\prime} \\ \text { who-A3 } & \text { where } & \text { COM } & \text { A3-die } & \text { PRO:man } & \text { E3-by } & \text { NCL } \\ \text { yalixh } & \text { icham } & & & & & \\ \text { little } & \text { old.man } & & & & & \end{array}$

'Who knows where the little old (bull) may have killed him' (Lit., 'Who knows where he died by the little old one') (NAJ/129)

Even though the inverse is syntactically intransitive, it is semantically a two-participant event clause. Unlike other monovalent clauses, the agent is an obligatory constituent in the inverse. Thus, in the inverse in $(40 b)$, the verb 'die' is clearly interpreted as the bivalent 'kill'. In the active clause, the same verb would be interpreted as the monovalent 'die', as in:

${ }^{10}$ This construction has been discussed by several authors, including Aissen (1987) for Tzotzil and Larsen (1994) for Awakatek. 
$\begin{array}{lllll}\text { (41) tuxa } & \text { chi- } \emptyset \text {-kam } & \text { naj } & \text { sacristan } & \text { tu' } \\ \text { almost } & \text { INC-A3-die } & \text { NCL } & \text { sexton } & \text { DIST }\end{array}$

'the sexton is about to die' (TX'I/164)

The Akatek inverse differs from the classical inverse of Algonquian (Dahlstrom 1986) in a number of ways. First, an intransitive verb is used rather than a syntactically transitive verb. Second, no obligatory semantic inversion is involved, i.e., an automatic inversion precipitated by the person, animacy, or definiteness hierarchies. ${ }^{11}$ Thus, in (42a) below, the second-person patient outranks the third-person agent, while in $(42 b)$ the first-person agent outranks the third-person patient. The same inverse structure is used in both:

(42a) Second-person PAT, third-person AGT

$\begin{array}{lllll}t u^{\prime} m i & \text { man-oj } & \text { ach-kam } & y \text { - } u \text { u } & e b^{\prime} \\ \text { maybe } & \text { NEG-IRR } & \text { A2s-die } & \text { E3-by } & \text { PRO:PL }\end{array}$

'Won't you be killed by them'?

(Lit., 'Won't you die by them?')

$\left(\mathrm{TX}^{\prime} \mathrm{I} / 89\right)$

(42b) Third-person PAT, first-person AGT

max $\emptyset$-kam naj w-uu

COM A3-die PRO:man E1s-by

'I killed him'

(Lit., 'He died by me') (TX'I/210)

The pragmatic nature of the Akatek inverse is also underscored by its use in clauses with two third-person participants. Thus in the text fragment below, the same event with two third-person participants is rendered first by an active direct clause in $(43 a)$, then by an inverse in $(43 b)$ :

(43a) Active direct

$\begin{array}{llll}x-\emptyset-y-i^{\prime}-o n-e l & e b^{\prime} & \text { xin } & y \text {-ib'an, } \ldots \\ \text { COM-A3s-E3-carry-ON-DIR:out } & \text { they then } & \text { E3-on }\end{array}$

'... they pulled it (the box) out, ...'

(43b) Inverse

$\begin{array}{llllll}j a & t u^{\prime} & \emptyset \text {-el } & y \text { - } u u & e b^{\prime} & \text { xin } \\ \text { water } & \text { DIST } & \text { A3-exit } & \text { E3-by } & \text { they then }\end{array}$

water DIST A3-exit E3-by they then

'they pulled it out of the water...'

(ALE 164-65)

(Lit., 'it got out of the water by them ...')

\footnotetext{
${ }^{11}$ See Dahlstrom (1986) as well as Klaiman (1992; 1993). However, as noted in Givón $(1994 a ; 1994 b)$, many inverse constructions involve only pragmatic inversion (topicality); and the same language may have both a semantic inverse (inverse alignment) and a pragmatic one (inverse voice) (Gildea 1994 and Payne, Hamaya, and Jacobs 1994).
} 
The next text fragment illustrates the opposite order; the same event with the same two participants (third person acting on first-person plural) is rendered first in the inverse, then in the active direct:

(44a) Inverse

$$
\begin{array}{lllll}
\text { tol-ab' } & \text { oj-ko-kam-oj } & \text { y-uu } & \text { naj } & \text { in-mam } \\
\text { SUB-EV } & \text { IRR-A1p-die-IRR } & \text { E3-by } & \text { NCL } & \text { E1s-father } \\
t u \text { ' } & \text { an } & & \\
\text { DIST } & \text { CL1s } \\
\text { '. . "my father is going to kill us", }
\end{array}
$$

(44b) xal tinani' k'am chi- $\emptyset$-w-al an ta...

but now NEG INC-A3-E1-tell CL1s COND

“ "if you don't know, tell the truth" [the girl said to the boy].

"Alright," said the boy, "the day after tomorrow you'll see.

Right now I'm not telling you that",

(44c) Active direct

$\begin{array}{llllll}\ldots & \text { ch-on-s-ma' } & k a m & n a j & a-m a m & t u \\ \text { INC-A1p-E3-hit } & \text { die } & \text { NCL } & \text { E2s-father } & \text { DIST }\end{array}$

'. . . if your father kills us'

(44d) Active direct

$\begin{array}{llll}s-m a \text { 'on-oj-ab' } & \text { kam } & \text { naj } & \text { xin... } \\ \text { E3-hit-A1p-EXH-EV } & \text { die } & \text { PRO } & \text { then } \\ \text { 'let him kill us ...' } & & & \end{array}$

The direct active 'kill' in $(44 c)$ and (44d) is lexicalized as the serial verb construction 'hit-die', with 'hit' taking the proper ergative and absolutive affixes and 'die' appearing as a bare nonfinite stem.

Most intransitive patient-oriented verbs ("unaccusative") can participate in such an inverse pattern. Some of them form stable pairs with specific transitive verbs that are used in the corresponding active direct clause. Thus, the intransitive kam 'die' of the inverse ( $44 a$ ) pairs with the combination ma' kam 'hit-die', 'kill' in the direct active ( $44 c$ and $44 d$ ). Likewise, the intransitive too 'go' in the inverse pairs with the transitive $i$ ' 'carry' in the active direct, etc. But many transitive verbs used in the direct active have no paired intransitive to be used in this type of inverse clause. Thus, for example, neither $i l$ 'see' nor oche 'want' has such paired intransitives. Such verbs have corresponding agented passives, however. As is shown further below, the pragmatic voice function of the agented passive in Akatek is rather similar to that of the inverse. 
TABLE 5

The Frequency Distribution of Voice Constructions in SEMANTICALly Transitive Clauses IN Chamorro Narrative TeXt (CoOREMan 1987)

\begin{tabular}{lrr}
\hline \hline Voice Construction & $\mathrm{N}$ & $\%$ \\
\hline Active direct & 601 & 72.0 \\
Inverse (in-) & 134 & 16.1 \\
Passive $(\mathrm{ma}$-) & 35 & 4.2 \\
Antipassive & 64 & 7.7 \\
\cline { 2 - 2 } Total & 834 & 100.0 \\
\hline
\end{tabular}

\section{Discourse-functional analysis of the Akatek voice constructions.}

4.1. Overall text frequency of voice constructions. There is a wellknown bias in the frequency of voice clauses in narrative, action-oriented text, so that active direct clauses are by far the most frequent in text, while the various passives, inverses, and antipassives each constitute a much smaller fraction (Cooreman 1987, Cooreman, Fox, and Givón 1984, Rude 1985, Thompson 1989, and Givón 1994b). To illustrate this bias, consider the frequency of Chamorro voice constructions given by Cooreman (1987), as shown in table 5 .

4.2. Topicality measurements. To assess the topicality of agents and patients in semantically transitive clauses, I used the quantitative text-based method initially developed by Givón (1983), modified by Wright and Givón (1987), and adapted to the study of pragmatic voice by Cooreman (1982; 1987); Cooreman, Fox, and Givón (1984), Rude (1985), Thompson (1989), and Givón (1994b). This method deals with two partially independent aspects of referential continuity-ANAPHORIC ACCESSIBILITY and CATAPHORIC PERSISTENCE. In general, one assumes that more topical (thematically important) referents tend to be both more accessible-thus more continuousanaphorically, and more persistent-thus continuous-cataphorically. The quantitative measures springing out of these assumptions are merely HEURISTIC, they do not purport to assess topicality ("thematic importance") directly. Rather, they measure anaphoric and cataphoric continuity of agent and patient NPs, and then infer topicality via the assumed correlation between continuity and topicality.

4.2.1. Referential distance. The first heuristic measure of topicality probes the agent's or patient's REFERENTIAL DISTANCE (RD) or anaphoric gap, that is, the number of clauses separating its present occurrence from its last occurrence in the preceding text. When the coreferential antecedent 
is found in the directly preceding clause, the value 1 is assigned. When the antecedent is found in the second or third clause from the present occurrence, the value $2 / 3$ is assigned. When no antecedent is found in the preceding three clauses, the value $>3$ is assigned. The results are then expressed as the frequency distribution of these three RD values in the total population of agents or patients. But mean values for the whole population may also be computed.

In general, highly topical referents, especially those coded as pronouns or zero anaphors, tend to have the RD value of 1 . Emphatic or topicalized NPs tend to have the RD value of 2-3 clauses. Less topical referents tend to have the RD value of $>3$. The diagnostic cutoff point between topical and nontopical referents is thus either between the values 1 and $>1$ or between the values $1-2-3$ and $>3$. The latter cutoff point was adopted for this study.

4.2.2. Topic persistence. The second measure is that of TOPIC PERSISTENCE (TP) or cataphoric continuity. The number of times the referent recurs within the next (cataphoric) ten clauses following its present occurrence is counted. TP values between 0 and 10 are most commonly recorded. The results are again expressed as frequency distribution of the various persistence values in the total population of agents or patients. Median values for the whole population may also be computed.

The TP measure has proven to be particularly useful in assessing the topicality of nominal referents regardless of anaphoric antecedence (Wright and Givón 1987). In general, more topical (thematically important) referents tend to have TP values $>2$, and less topical referents values of $0-2$.

4.3. Akatek texts. The texts used in this study come from a body of Akatek narratives collected and transcribed by Peñalosa (Peñalosa and Say 1992). These narratives were checked with Roberto Franco from San Miguel Acatán by myself and other students of the field methods class of 1992-93 at the University of Oregon. The texts were glossed and separated into clauses by using the IT computer program. Only semantically transitive clauses were considered. The five longest narratives of the collectionrenamed as yistil, tx'itaj, naj, jun, and b'alam-were used.

\section{Results.}

5.1. Overall text frequency of voice constructions. The overall text frequency of the eight voice constructions studied is given in table 6 . Two types of antipassive, the antipassive with demoted patient and the incorporating antipassive, were not found in our corpus.

As expected, the active direct clause is the most common voice type in our narrative texts, with the various other voices following far behind. This conforms to the distributional findings elsewhere (see, e.g., table 5). 
TABLE 6

Overall Text Frequency of Voice Constructions of Semantically Transitive Clauses in Akatek

\begin{tabular}{lrr}
\hline \hline & \multicolumn{1}{c}{ N } & $\%$ \\
\hline Active direct (V-first) & 637 & 76 \\
Patient-in-focus (PAT-V-AGT) & 47 & 6 \\
Agent-in-focus (AGT-V-PAT) & 24 & 3 \\
Absolutive antipassive & 42 & 5 \\
VP nominalization & 9 & 1 \\
Impersonal passive & 27 & 3 \\
Agented passive & 17 & 2 \\
Inverse & 36 & 4 \\
Total & 839 & 100 \\
\hline
\end{tabular}

TABLE 7

Distribution of RefERential Distance (RD) Values for agents and Patients in Active Direct Clauses

\begin{tabular}{|c|c|c|c|c|}
\hline \multirow[b]{2}{*}{$\mathrm{RD}$} & \multicolumn{2}{|c|}{ Agent } & \multicolumn{2}{|c|}{ Patient } \\
\hline & $\mathrm{N}$ & $\%$ & $\mathrm{~N}$ & $\%$ \\
\hline 1 & 428 & 67.2 & 220 & 34.5 \\
\hline $2-3$ & 154 & 24.3 & 128 & 20.1 \\
\hline$>3$ & 54 & 8.5 & 289 & 45.4 \\
\hline Total & 637 & 100.0 & 637 & 100.0 \\
\hline
\end{tabular}

TABLE 8

Distribution of Referential Distance (RD) Values for Agents and Patients in Patient-in-Focus Clauses

\begin{tabular}{|c|c|c|c|c|}
\hline \multirow[b]{2}{*}{$\mathrm{RD}$} & \multicolumn{2}{|c|}{ Agent } & \multicolumn{2}{|c|}{ Patient } \\
\hline & $\mathrm{N}$ & $\%$ & $\mathrm{~N}$ & $\%$ \\
\hline 1 & 26 & 55.3 & 16 & 34.0 \\
\hline $2-3$ & 19 & 40.4 & 10 & 21.3 \\
\hline$>3$ & 2 & 4.3 & 21 & 44.7 \\
\hline Total & 47 & 100.0 & 47 & 100.0 \\
\hline
\end{tabular}

5.2. Referential distance (RD). Tables 7 through 14 summarize the results of the referential distance (RD) measure for agents and patients in the eight voice constructions.

The RD values for agents and patients in Akatek voice clauses may be summarized by conflating the values 1-2-3 (high topicality) and contrasting 
TABLE 9

Distribution of ReFERENTIAL Distance (RD) Values for Agents and Patients in Agent-IN-Focus Clauses

\begin{tabular}{|c|c|c|c|c|}
\hline \multirow[b]{2}{*}{$\mathrm{RD}$} & \multicolumn{2}{|c|}{ Agent } & \multicolumn{2}{|c|}{ Patient } \\
\hline & $\mathrm{N}$ & $\%$ & $\mathrm{~N}$ & $\%$ \\
\hline 1 & 10 & 41.7 & 7 & 29.2 \\
\hline $2-3$ & 4 & 16.6 & 5 & 20.8 \\
\hline$>3$ & 10 & 41.7 & 12 & 50.0 \\
\hline Total & 24 & 100.0 & 24 & 100.0 \\
\hline
\end{tabular}

TABLE 10

Distribution of Referential Distance (RD) Values for agents and Patients in Absolutive Antipassive Clauses

\begin{tabular}{|c|c|c|c|c|}
\hline \multirow[b]{2}{*}{$\mathrm{RD}$} & \multicolumn{2}{|c|}{ Agent } & \multicolumn{2}{|c|}{ Patient } \\
\hline & $\mathrm{N}$ & $\%$ & $\mathrm{~N}$ & $\%$ \\
\hline 1 & 28 & 66.7 & - & 0.0 \\
\hline $2-3$ & 11 & 26.2 & - & 0.0 \\
\hline$>3$ & 3 & 7.1 & 42 & 100.0 \\
\hline Total & 42 & 100.0 & 42 & 100.0 \\
\hline
\end{tabular}

TABLE 11

Distribution of REFERENTIAL Distance (RD) VALUES For AgENTS ANd PatiENTS IN VP Nominalization Clauses

\begin{tabular}{|c|c|c|c|c|}
\hline \multirow[b]{2}{*}{$\mathrm{RD}$} & \multicolumn{2}{|c|}{ Agent } & \multicolumn{2}{|c|}{ Patient } \\
\hline & $\mathrm{N}$ & $\%$ & $\mathrm{~N}$ & $\%$ \\
\hline 1 & 6 & 66.7 & - & 0.0 \\
\hline $2-3$ & 3 & 33.3 & 3 & 33.3 \\
\hline$>3$ & - & 0.0 & 6 & 66.7 \\
\hline Total & 9 & 100.0 & 17 & 100.0 \\
\hline
\end{tabular}


TABLE 12

Distribution of Referential Distance (RD) VAlues for Agents and Patients in IMPERsonal Passive Clauses

\begin{tabular}{|c|c|c|c|c|}
\hline \multirow[b]{2}{*}{ RD } & \multicolumn{2}{|c|}{ Agent } & \multicolumn{2}{|c|}{ Patient } \\
\hline & $\mathrm{N}$ & $\%$ & $\mathrm{~N}$ & $\%$ \\
\hline 1 & 1 & 3.7 & 16 & 59.2 \\
\hline $2-3$ & 1 & 3.7 & 6 & 22.2 \\
\hline$>3$ & 25 & 92.6 & 5 & 18.6 \\
\hline Total & 27 & 100.0 & 27 & 100.0 \\
\hline
\end{tabular}

TABLE 13

Distribution of Referential Distance (RD) Values for Agents and Patients in Agented Passive Clauses

\begin{tabular}{|c|c|c|c|c|}
\hline \multirow[b]{2}{*}{ RD } & \multicolumn{2}{|c|}{ Agent } & \multicolumn{2}{|c|}{ Patient } \\
\hline & $\mathrm{N}$ & $\%$ & $\mathrm{~N}$ & $\%$ \\
\hline 1 & 8 & 47.0 & 8 & 47.0 \\
\hline $2-3$ & 4 & 23.5 & 5 & 29.4 \\
\hline$>3$ & 5 & 29.5 & 4 & 23.6 \\
\hline Total & 17 & 100.0 & 17 & 100.0 \\
\hline
\end{tabular}

TABLE 14

Distribution of Referential Distance (RD) Values For Agents and Patients in Inverse Clauses

\begin{tabular}{|c|c|c|c|c|}
\hline \multirow[b]{2}{*}{$\mathrm{RD}$} & \multicolumn{2}{|c|}{ Agent } & \multicolumn{2}{|c|}{ Patient } \\
\hline & $\mathrm{N}$ & $\%$ & $\mathrm{~N}$ & $\%$ \\
\hline 1 & 19 & 52.8 & 23 & 63.9 \\
\hline $2-3$ & 9 & 25.0 & 9 & 25.0 \\
\hline$>3$ & 8 & 22.2 & 4 & 11.1 \\
\hline Total & 36 & 100.0 & 36 & 100.0 \\
\hline
\end{tabular}


TABLE 15

Percentage of Agents and Patients with RD Values 1-2-3 (High Topicality) AND $>3$ (Low Topicality) In The Various AKatek Voice Constructions

\begin{tabular}{|c|c|c|c|c|}
\hline \multirow[b]{2}{*}{ Voice Construction } & \multicolumn{2}{|c|}{ Agent } & \multicolumn{2}{|c|}{ Patient } \\
\hline & $1-3$ & $>3$ & $1-3$ & $>3$ \\
\hline \multicolumn{5}{|l|}{ Active direct: } \\
\hline Active direct (V-first) & 91.5 & 8.5 & 54.6 & 45.4 \\
\hline Patient-in-focus (PAT-V-AGT) & 95.7 & 4.3 & 55.3 & 44.7 \\
\hline \multicolumn{5}{|l|}{ ??????: } \\
\hline Agent-in-focus (AGT-V-PAT) & 58.3 & 41.7 & $\mathbf{5 0 . 0}$ & 50.0 \\
\hline \multicolumn{5}{|l|}{ Antipassive: } \\
\hline Absolutive antipassive & 92.9 & 7.1 & - & 100.0 \\
\hline VP nominalization & 100.0 & - & 33.3 & 66.7 \\
\hline \multicolumn{5}{|l|}{ Passive: } \\
\hline Impersonal passive & 7.4 & 92.6 & 81.4 & 18.6 \\
\hline \multicolumn{5}{|l|}{ Inverse: } \\
\hline Agented passive & 70.5 & 29.5 & 77.4 & 23.6 \\
\hline Inverse & 77.8 & 22.2 & 88.9 & 11.1 \\
\hline
\end{tabular}

them with the value $>3$ (low topicality). This summary, contrasting the eight voice constructions, is given in table 15 , with the constructions grouped tentatively into the main pragmatic voices.

The active direct and the patient-in-focus clauses conform closely to the active direct voice prototype, with 91-95 percent of the agents and 54-55 percent of the patients in the high-topicality range. The status of the transitive agent-in-focus construction is puzzling, in that the agent seems much lower in topicality (58 percent, with 1-3 RD value), while the patient remains essentially at the same level as the other two transitive clauses (50 percent). This distribution resembles most closely the INVERSE functional prototype, where both agent and patient are topical.

Both the absolutive antipassive and the VP nominalization conform closely to the antipassive functional prototype, with 90-100 percent of the agents in the high-topicality range, and 100 percent to 66 percent of the patients, respectively, in the low-topicality range. In other words, while the agent remains as topical as in the active, the patient is severely detopicalized.

The agentless passive conforms to the passive functional prototype, with 92 percent of the agents in the low-topicality range and 81 percent of the 
TABLE 16

Distribution of Topic Persistence (TP) Values for Agents and Patients in Active Direct Clauses (V-First)

\begin{tabular}{|c|c|c|c|c|}
\hline \multirow[b]{2}{*}{ TP } & \multicolumn{2}{|c|}{ Agent } & \multicolumn{2}{|c|}{ Patient } \\
\hline & $\mathrm{N}$ & $\%$ & $\mathrm{~N}$ & $\%$ \\
\hline $0-2$ & 50 & 7.8 & 376 & 59.0 \\
\hline$>2$ & 587 & 92.2 & 261 & 41.0 \\
\hline Total & 637 & 100.0 & 637 & 100.0 \\
\hline
\end{tabular}

TABLE 17

Distribution of Topic Persistence (TP) VAlues for Agents and Patients in Patient-in-Focus Clauses (PAT-V-AGT)

\begin{tabular}{|c|c|c|c|c|}
\hline \multirow[b]{2}{*}{$\mathrm{TP}$} & \multicolumn{2}{|c|}{ Agent } & \multicolumn{2}{|c|}{ Patient } \\
\hline & $\mathrm{N}$ & $\%$ & $\mathrm{~N}$ & $\%$ \\
\hline $0-2$ & 4 & 8.5 & 18 & 38.3 \\
\hline$>2$ & 43 & 91.5 & 29 & 61.7 \\
\hline Total & 47 & 100.0 & 47 & 100.0 \\
\hline
\end{tabular}

patients in the high-topicality range. In other words, the patient is highly topical, while the agent is severely detopicalized.

Finally, both the agented passive and the inverse clause conform rather closely to the inverse functional prototype, with 70-77 percent of the agents in the high-topicality range but also $77-88$ percent of the patients highly topical.

5.3 Topic persistence (TP). Tables 16 through 23 summarize the distribution of low $(0-2)$ and high $(>2)$ topic persistence (TP) values for agents and patients in the various voice constructions.

The TP values for agents and patients in the eight voice clauses in Akatek may now be summarized, with the values $0-2$ considered low topicality and the values $>2$ high topicality. The summary is given in table 24 , with the construction grouped tentatively into the main pragmatic voice types.

The active direct and patient-in-focus clauses, with some difference, conform to the active direct voice functional prototype, with 91-92 percent of the agents and 40-60 percent of the patients in the high-topicality range. However, the patient-in-focus construction clearly topicalizes the patient above the level found in the V-first (unmarked) active direct clause. In this sense, the patient-in-focus clause, with its PAT-V-AGT, resembles an INVERSE. 
TABLE 18

Distribution of Topic Persistence (TP) Values for agents and Patients in Agent-in-Focus Clauses (AGT-V-PAT)

\begin{tabular}{crrrrrr}
\hline \hline & \multicolumn{2}{c}{ Agent } & & \multicolumn{2}{c}{ Patient } \\
\cline { 2 - 3 } \cline { 6 - 7 } TP & N & $\%$ & & N & $\%$ \\
\hline $0-2$ & 9 & & 37.5 & & 15 & 62.5 \\
$>2$ & 15 & & 62.5 & & 9 & 37.5 \\
Total & 24 & & 100.0 & & 24 & 100.0 \\
\hline
\end{tabular}

TABLE 19

Distribution of Topic Persistence (TP) Values for agents and Patients in Absolutive Antipassive Clauses

\begin{tabular}{crrrrrr}
\hline \hline & \multicolumn{2}{c}{ Agent } & & \multicolumn{2}{c}{ Patient } \\
\cline { 2 - 3 } \cline { 5 - 6 } TP & N & $\%$ & & N & $\%$ \\
\hline $0-2$ & 1 & & 2.4 & & 42 & $\mathbf{1 0 0 . 0}$ \\
$>2$ & 41 & & 97.6 & & - & - \\
\cline { 6 - 7 } Total & 42 & & 100.0 & & 42 & 100.0 \\
\hline
\end{tabular}

TABLE 20

Distribution of Topic Persistence (TP) Values for Agents and Patients in VP Nominalization Clauses

\begin{tabular}{|c|c|c|c|c|}
\hline \multirow[b]{2}{*}{ TP } & \multicolumn{2}{|c|}{ Agent } & \multicolumn{2}{|c|}{ Patient } \\
\hline & $\mathrm{N}$ & $\%$ & $\mathrm{~N}$ & $\%$ \\
\hline $0-2$ & - & - & 7 & 77.8 \\
\hline$>2$ & 9 & 100.0 & 2 & 22.2 \\
\hline Total & 9 & 100.0 & 9 & 100.0 \\
\hline
\end{tabular}

TABLE 21

Distribution of Topic Persistence (TP) Values for Agents and Patients in Impersonal Passive Clauses

\begin{tabular}{|c|c|c|c|c|}
\hline \multirow[b]{2}{*}{$\mathrm{TP}$} & \multicolumn{2}{|c|}{ Agent } & \multicolumn{2}{|c|}{ Patient } \\
\hline & $\mathrm{N}$ & $\%$ & $\mathrm{~N}$ & $\%$ \\
\hline $0-2$ & 26 & 96.3 & 10 & 37.0 \\
\hline$>2$ & 1 & 3.7 & 17 & 63.0 \\
\hline Total & 27 & 100.0 & 27 & 100.0 \\
\hline
\end{tabular}


TABLE 22

Distribution of TOPIC PERsistence (TP) VALUES For Agents and Patients in Agented Passive Clauses

\begin{tabular}{|c|c|c|c|c|}
\hline \multirow[b]{2}{*}{$\mathrm{TP}$} & \multicolumn{2}{|c|}{ Agent } & \multicolumn{2}{|c|}{ Patient } \\
\hline & $\mathrm{N}$ & $\%$ & $\mathrm{~N}$ & $\%$ \\
\hline $0-2$ & 5 & 29.5 & 3 & 17.6 \\
\hline$>2$ & 12 & 70.5 & 14 & 82.4 \\
\hline Total & 17 & 100.0 & 17 & 100.0 \\
\hline
\end{tabular}

TABLE 23

Distribution of Topic Persistence (TP) Values For Agents and Patients in InVerse Clauses

\begin{tabular}{|c|c|c|c|c|}
\hline \multirow[b]{2}{*}{$\mathrm{TP}$} & \multicolumn{2}{|c|}{ Agent } & \multicolumn{2}{|c|}{ Patient } \\
\hline & $\mathrm{N}$ & $\%$ & $\mathrm{~N}$ & $\%$ \\
\hline $0-2$ & 9 & 25.0 & 12 & 33.4 \\
\hline$>2$ & 27 & 75.0 & 24 & 66.6 \\
\hline Total & 36 & 100.0 & 36 & 100.0 \\
\hline
\end{tabular}

The functional status of the transitive agent-in-focus construction is again puzzling. While the agent is lower in topicality than the V-first active direct clause-62 percent in the $>2$ range vs. 92 percent, respectively-the patient remains at the level of the active direct clause (37 vs. 41 percent, respectively). Functionally, this clause type again resembles, though only partially, an INVERSE.

Once again, the absolutive antipassive and the VP nominalization conform closely to the antipassive functional prototype, with 97-100 percent of the agents in the high-topicality range and 100 percent to 77 percent of the patients, respectively, in the low-topicality range. In other words, while the agent in both constructions remains as topical as in the active direct, the patient is severely detopicalized.

The impersonal (agentless) passive again conforms closely to the passive functional prototype, with 96 percent of the agents in the low-topicality range and 63 percent of the patients in the high-topicality range. In other words, the patient is relatively topical, but the agent has been severely detopicalized.

Finally, both the agented passive and the inverse clause again conform to the inverse functional prototype, with 70-75 percent of the agents in the high-topicality range but also 66-82 percent of the patients highly topical. 
TABLE 24

Percentage of Agents and Patients with TP Values 0-2 (Low Topicality) AND >2 (High Topicality) in the Various AKatek Voice Constructions

\begin{tabular}{|c|c|c|c|c|}
\hline \multirow[b]{2}{*}{ Voice Construction } & \multicolumn{2}{|c|}{ Agent } & \multicolumn{2}{|c|}{ Patient } \\
\hline & $0-2$ & $>2$ & $0-2$ & $>2$ \\
\hline \multicolumn{5}{|l|}{ Active direct: } \\
\hline Active direct (V-first) & 7.8 & 92.2 & $\mathbf{5 9 . 0}$ & 41.0 \\
\hline Patient-in-focus (PAT-V-AGT) & 8.5 & 91.5 & 38.3 & 61.7 \\
\hline \multicolumn{5}{|l|}{ ??????: } \\
\hline Agent-in-focus (AGT-V-PAT) & 37.5 & 62.5 & 62.5 & 37.5 \\
\hline \multicolumn{5}{|l|}{ Antipassive: } \\
\hline Absolutive antipassive & 2.4 & 97.6 & 100.0 & - \\
\hline VP nominalization & - & 100.0 & 77.8 & 22.2 \\
\hline \multicolumn{5}{|l|}{ Passive: } \\
\hline Impersonal passive & 96.3 & 3.7 & 37.0 & 63.0 \\
\hline \multicolumn{5}{|l|}{ Inverse: } \\
\hline Agented passive & 29.5 & 70.5 & 17.6 & 82.4 \\
\hline Inverse & 25.0 & 75.0 & 33.4 & 66.6 \\
\hline
\end{tabular}

6. Discussion. Unlike other studies of Mayan voice constructions, this study employed a text-based quantitative methodology in trying to assess the functional correlates of the various Akatek voice clauses. In some instances, this study has confirmed the intuitions of the previous structure-oriented studies. At the same time, it also challenges several of their assumptions.

The quantitative heuristic methods of assessing topicality have made it possible to clearly identify the syntactic structures that pair with all four main voice functions in Akatek-active direct, inverse, passive, and antipassive. With the partial exception of the two transitive constructions that use word-order variation - the patient-in-focus and agent-in-focus constructions, all other clause-types tested conform closely to their suggested functional prototypes. Thus, for example, we have shown that two clause types-absolutive antipassive and VP nominalization-conform to the functional profile of antipassive voice, i.e., with highly topical agent and severely detopicalized patient.

Likewise, both our heuristic measures suggest that Akatek has at least two inverse constructions, one previously identified as an "agented pas- 
sive," the other a newly identified inverse. Both conform closely to the inverse functional prototype, that of a highly topical patient but also a topical agent.

Of the three active transitive clauses, V-first, PAT-V-AGT, and AGT-VPAT, our study tags the V-first clause as the prototype transitive voice clause. The other two, while not conforming to the active direct prototypes completely, involve neither a drastic detopicalization of the agent nor a drastic detopicalization of the patient. In other words, they neither clearly conform to the passive nor to the antipassive prototype. If anything, both constructions resemble to some extent the functional prototype of the inverse. This study further suggests that the agent-in-focus (AGT-V-PAT) clause is functionally not an antipassive in Akatek. Further study of voice function of both focus clauses may be in order, in Akatek as well as in other Mayan languages.

To my knowledge, this is the first study in Mayan linguistics to clearly identify an INVERSE voice function and associate it with a specific construction, in fact two constructions. The inverse function of the agented passive in Akatek is reminiscent of similar findings in Spanish (Hidalgo 1994). But in addition I have identified a unique inverse construction in Akatek, one never before described as a voice alternation in the Mayan literature.

Finally, the quantitative results reported here conform closely to previous cross-linguistic studies that identified the pragmatic voice function of various transitive and detransitive clauses. Those studies have tagged the passive as a voice in which the agent is severely detopicalized and the antipassive as the voice in which the patient is likewise detopicalized. They also tag the inverse as the voice most resembling the active direct, in that both agent and patient remain topical, but the patient is consistently more topical than it is in the active direct voice. By demonstrating that these crosslinguistic findings make sense in Akatek, we have also shown the value of applying a universal functional approach, and its concomitant typological comparative approach, to the problems of syntactic analysis, in Mayan and perhaps elsewhere. ${ }^{12}$

\footnotetext{
${ }^{12}$ The following abbreviations are used in this paper: A absolutive marker; AGT semantic agent; AGTFOC agent-in-focus marker; AP antipassive; BEN benefactive; CL clitic; COL collective; COM completive; COND conditional; DAT semantic dative; DEFPL definite plural; DIR directional; DIST distal demonstrative; DUR durative; $\mathrm{E}$ ergative and possessor marker; EV evidential; EX existential; EXH exhortative; EXCL exclusive; FOC focus; FUT future; INC incompletive; INCL inclusive; INTR intransitive thematic vowel; IRR irrealis; LOC locative; NCL noun classifier; NEG negative; NEG.COM negative completive; NF nonfinite; NOM nominalizer; p plural; PASS passive; PAT semantic patient; PF perfective; PL plural; PRO pronoun; PROG progressive aspect; PROX proximal demonstrative; s singular; SUB subordinator; TR transitive thematic vowel; 1, 2, 3 first, second, third person.
} 


\section{REFERENCES}

AISSEN, JudiTH. 1987. Tzotzil Clause Structure. Dordrecht: Reidel.

1990. Una teoría de voz para idiomas Mayas. Lecturas Sobre la Lingüística Maya, ed. Nora C. England and Stephen R. Elliott, pp. 399-419. Guatemala: Centro de Investigaciones Regionales de Mesoamérica.

Ayres, GlenN ThOMPson. 1983. The antipassive "voice" in Ixil. IJAL 49:20-45.

Bricker, Victoria ReIFLER. 1978. Antipassive constructions in Yucatec Maya. Papers in Mayan Linguistics, ed. Nora C. England, pp. 3-24. Columbia: University of Missouri.

COOREMAN, ANN. 1982. Topicality, ergativity and transitivity in narrative discourse: evidence from Chamorro. Studies in Language 6:343-74.

1987. Transitivity and Discourse Continuity in Chamorro Narratives. Berlin: Mouton de Gruyter.

COOREMAN, AnN; Barbara Fox; AND TALMy Givón. 1984. The discourse definition of ergativity. Studies in Language 8:1-39.

Craig, Colette G. 1977. The Structure of Jacaltec. Austin: University of Texas Press. . 1979. The antipassive and Jacaltec. Papers in Mayan Linguistics, ed. L. Martin, pp. 13964. Columbia, Mo.: Lucas Bros. Publishers.

Dahlstrom, Amy L. 1986. Plains Cree morphosyntax. Ph.D. dissertation, University of California, Berkeley.

DAKIN, KAREN. 1976. Acatec (Kanjobal) texts. Mayan Texts I, ed. L. Furbee, IJAL-NATS, vol. 1, no. 1, pp. 123-36. Chicago: University of Chicago Press.

DAYLEY, JON P. 1983. Voice and ergativity in Mayan languages. Studies in Mesoamerican Linguistics, ed. A. Schlichter, W. L. Chafe, and L. Hinton, pp. 5-119. Reports from the Survey of California and Other Indian Languages. Santa Barbara: University of California.

1985. Voice in Tzutujil. Grammar Inside and Outside the Clause: Some Approaches to Theory from the Field, ed. Johanna Nichols and Anthony C. Woodbury, pp. 192-226. Cambridge: Cambridge University Press.

DeLANCEY, SCOTT. 1981a. An interpretation of split ergativity and related patterns. Language 51:626-57.

1981b. The category of direction in Tibeto-Burman. Linguistics of the Tibeto-Burman Area 6:83-101.

Dixon, R. M. W. 1979. Ergativity. Language 55:59-138.

ENGLAND, NoRA C. 1983. A Grammar of Mam. Austin: University of Texas Press. . 1988. Mam voice. Passive and Voice, ed. M. Shibatani, pp. 525-46. Amsterdam: John Benjamins.

GILDEA, SPIKE. 1994. Semantic and pragmatic inverse: 'inverse alignment' vs. 'inverse voice' in Carib of Surinam. Voice and Inversion, ed. T. Givón, pp. 187-230. Amsterdam: John Benjamins.

Grvón, Talmy, ed. 1983. Topic Continuity in Discourse: A Quantified Text-Based Study. Amsterdam: John Benjamins.

1984. Syntax: A Functional-Typological Introduction. Vol. 1. Amsterdam: John Benjamins. Benjamins.

1990. Syntax: A Functional-Typological Introduction. Vol. 2. Amsterdam: John

. 1994a. The pragmatics of de-transitive voice: functional and typological aspects of inversion. Voice and Inversion, ed. T. Givón, pp. 3-44. Amsterdam: John Benjamins. , ed. 1994b. Voice and Inversion. Amsterdam: John Benjamins.

HIDALGO, RaQuel. 1994. The pragmatics of de-transitive voice in Spanish: from passive to inverse? Voice and Inversion, ed. T. Givón, pp. 169-86. Amsterdam: John Benjamins.

Hopper, Paul, and SANDra A. Thompson. 1980. Transitivity in grammar and discourse. Language 56:251-99. 
KLAIMAN, M. H. 1992. Inverse languages. Lingua 88:227-61.

. 1993. The relationship of inverse voice and head-marking in Arizona Tewa and other

Tanoan languages. Studies in Languages 17:343-70.

LANSING, DonalD. n.d. Vocabulario de Jacalteco-K'anjob'al-Migueleño. Ms.

LARSEN, Thomas W. 1990. Notas sobre ergatividad en la gramática Maya. Lecturas Sobre la Lingǘstica Maya, ed. Nora C. England and Stephen R. Elliott, pp. 319-34. Guatemala: Centro de Investigaciones Regionales de Mesoamérica.

. 1994. Deictic and non-deictic directionals in Awakatek. Estudios en Lenguas Mayas, Función 15/16:169-210.

Larsen, Thomas W., and William M. Norman. 1979. Correlates of ergativity in Mayan grammar. Ergativity: Towards a Theory of Grammatical Relations, ed. Frans Planck, pp. 34770. London: Academic Press.

Martin, LaURa. 1977. Positional roots in Kanjobal (Mayan). Ph.D. dissertation, University of Florida.

MAXWELL, JUDITH. 1976. Chuj intransitives: or when can an intransitive verb take an object. Mayan Linguistics, vol. 1, ed. Marlys McClaran, pp. 128-40. Los Angeles: American Indian Studies Center, University of California.

Mondloch, James L. 1981. Voice in Quiche-Maya. Ph.D. dissertation, State University of New York, Albany.

Payne, Doris L. 1994. The Tupi-Guaraní inverse. Voice: Form and Function, ed. Barbara Fox and Paul Hopper, pp. 313-40. Amsterdam: John Benjamins.

Payne, Doris L.; Mitsuyo Hamaya; And Peter Jacobs. 1994. Active, inverse and passive in Maasai. Voice and Inversion, ed. T. Givón, pp. 283-316. Amsterdam: John Benjamins.

Peñalosa, Fernando. 1987. Major syntactic structures of Acatec (dialect of San Miguel Acatán). IJAL 53:281-310.

. 1990. The Merchant and His Wife, an Akatek Mayan folktale. Latin American Indian Literatures Journal 6:97-129.

Peñalosa, Fernando, and Pedro Miguel Say. 1991 a. Naj unin yetoj no' Swakax, Naj txonwom yetoj yistil, Maltin k'uxum us. Los Angeles: Ediciones IXIM.

.1991b. Yik'tial eb' najo tx 'itaj. Los Angeles: Ediciones IXIM.

. 1991c. Cuentos Pícaros de Don Pedro Miguel Say. Los Angeles: Ediciones IXIM.

. 1992. Cuentos de Don Pedro Miguel Say. Los Angeles: Ediciones IXIM.

ROLAND, KaTY. 1994. The pragmatics of Modern Greek voice: active, inverse and passive. Voice and Inversion, ed. T. Givón, pp. 233-60. Amsterdam: John Benjamins.

Rude, NoEL. 1985. Studies in Nez Perce grammar and discourse. Ph.D. dissertation, University of Oregon, Eugene.

1994. Direct, inverse and passive in Northwest Sahaptin. Voice and Inversion, ed. T. Givón, pp. 101-19. Amsterdam: John Benjamins.

SCHÜle, SUSANNE. 1993. Word order flexibility in Akatek. M.A. thesis, University of Oregon, Eugene.

Smith-Stark, Thomas C. 1976. The antipassive in Jilopequeño Pocomam. Ms.

. 1978. The Mayan antipassive: some facts and fictions. Papers in Mayan Linguistics, ed. Nora C. England, pp. 169-87. Columbia: University of Missouri.

Thompson, ChaD. 1989. Voice and obviation in Athabaskan and other languages. Ph.D. dissertation, University of Oregon, Eugene.

1994. Passive and inverse constructions. Voice and Inversion, ed. T. Givón, pp. 4763. Amsterdam: John Benjamins.

Wright, SuZANNE S., AND TALMY Givón. 1987. The pragmatics of indefinite reference. Studies in Language 11:1-33.

Zavala, Roberto. 1991. Los sistemas clasificatorios en el kanjobal de San Miguel Acatán. Guadalajara: Universidad de Guadalajara.

1992. El kanjobal de San Miguel Acatán. México: UNAM. 
1993a. El acateco de la frontera sur. México: COLMEX.

. 1993b. Clause integration with verbs of motion in Mayan languages. M.A. thesis, University of Oregon, Eugene.

1994. Se les está moviendo el tapete: Gramaticalización de verbos de movimiento en akateko. Memorias del II Encuentro de Lingüística en el Noroeste, vol. 2, pp. 101-44. Hermosillo: Universidad de Sonora.

. 1995. Inverse alignment in Wastek. Estudios en Lenguas Mayas, Función 15/16:27-81. 